\title{
Hybrid controller of energy storage and renewable DG for congestion management
}

DOI:

10.1109/PESGM.2012.6345393

Link to publication record in Manchester Research Explorer

\section{Citation for published version (APA):}

Alnaser, S. W., \& Ochoa, L. F. (2012). Hybrid controller of energy storage and renewable DG for congestion management. In IEEE Power and Energy Society General Meeting/IEEE Power Energy Soc. Gen. Meet. https://doi.org/10.1109/PESGM.2012.6345393

\section{Published in:}

IEEE Power and Energy Society General Meeting|IEEE Power Energy Soc. Gen. Meet.

\section{Citing this paper}

Please note that where the full-text provided on Manchester Research Explorer is the Author Accepted Manuscript or Proof version this may differ from the final Published version. If citing, it is advised that you check and use the publisher's definitive version.

\section{General rights}

Copyright and moral rights for the publications made accessible in the Research Explorer are retained by the authors and/or other copyright owners and it is a condition of accessing publications that users recognise and abide by the legal requirements associated with these rights.

\section{Takedown policy}

If you believe that this document breaches copyright please refer to the University of Manchester's Takedown Procedures [http://man.ac.uk/04Y6Bo] or contact uml.scholarlycommunications@manchester.ac.uk providing relevant details, so we can investigate your claim.

\section{OPEN ACCESS}




\title{
Hybrid Controller of Energy Storage and Renewable DG for Congestion Management
}

\author{
Sahban W. Alnaser, Graduate Student Member, IEEE, and Luis F. Ochoa, Member, IEEE
}

\begin{abstract}
High penetration of renewable energy resources in distribution networks might lead to congestion issues in some corridors (lines) of the existing circuits, primarily during minimum demand scenarios. The adoption of active network management (ANM) schemes can effectively manage the power output of renewable distributed generation (i.e., curtailment) to prevent thermal constraint violation. However, this approach results (as expected) in lower contributions of low-carbon electricity generation to the system, hence lower revenues. By incorporating energy storage systems, wind farms could improve their capacity factor. Energy storage systems can be used to deal with congestion issues, leaving curtailment as the last resort. This paper proposes a novel (pseudo) real-time hybrid controller of wind power and energy storage to manage congestion in a monitored corridor based on pre-processed historical data. The year-long, hourly results show that the proposed scheme responds effectively to the thermal constraints allowing the harvesting of more wind energy.
\end{abstract}

Index Terms-- Energy Storage, wind power, active network management, smart distribution networks.

\section{INTRODUCTION}

$\mathrm{D}$ ISTRIBUTION networks in the UK and most courtiers in Europe are increasingly required to host more renewable distributed generation (DG) capacity in order to help their governments meet their corresponding targets of electricity generated from low carbon technologies by 2020 (with a European average of $20 \%$ ).

The inherent variability and (in general) unpredictable nature of renewable electricity generation, and the noncoincidental pattern between renewable power output and demand restrict the capability of distribution network operators (DNOs) to accommodate large volumes of renewable generation capacity. During periods of, for instance, high wind speeds (resulting in nominal capacity outputs of wind turbines) and low demand, the distribution network might face reverse current flowing upstream which may result in voltages above the statutory limits, overloads of the installed assets (e.g., lines, transformers), issues with the protection system, etc. [1]-[4]. Currently, most DNOs avoid these issues by either: limiting the installed DG capacity that could be connected at a given location in a way that no issue arises; or upgrading the corresponding assets that would

The authors are with the Electrical Energy and Power Systems (EEPS) Group, School of Electrical and Electronic Engineering, The University of Manchester, U.K. (email: sahban.alnaser@postgrad.manchester.ac.uk; luis_ochoa@ieee.org) otherwise be negatively affected (e.g., reinforcing lines) - to be paid (in most cases) by the DG developer.

With this "fit and forget" approach (also known in the UK as firm generation connection), DG can freely operate up to its rated output. However, this approach might considerably sterilize the potential hosting capacity of a distribution network, it is seen as a significant CAPEX for DG developers, and might also result in a poor utilization of assets given the variability of renewable sources. Thus, some DNOs are adopting arrangements where it is possible to trip a DG plant in case their power output results in the violation of a constraint (e.g., thermal, reverse power flow, etc.). This is known as non-firm generation connections.

In the last few years, a few DNOs have implemented what is called active network management (ANM), a building block towards Smart Distribution Networks [5]. By applying ANM, DNOs actively manage the power output of renewable DG plants (particularly wind farms) in order to avoid network constraint violations. This approach, although requires communication infrastructure and the curtailment of wind generation, allows the deployment of larger volumes of renewable DG capacity without the need of expensive reinforcements.

To increase further the harvesting of low-carbon electricity, or, in other words, to minimize the curtailment of the wind farm, a technology that could be integrated to the above mentioned ANM approach is electric energy storage. Storage technologies range from electrochemical systems (flow batteries and normal cell batteries), to kinetic energy systems (flywheels), to magnetic energy systems (superconducting energy storage) [6]. With energy storage it is possible to integrate wind farms in a more sophisticated way where network constraints are actively managed and curtailment is reduced (excess of generation is stored locally and released later when constraints are not an issue).

Available and future technologies of energy storage under development are discussed in [7]-[9], providing different aspects of applications in power systems as well as economic analyses. Different types of battery energy storage systems (BESS), of particular interest for DNOs given its commercial readiness, are examined from various perspectives in [10]. Some of the most promising applications for distribution networks include:

- Modification of real and reactive power flows to the benefit of the network [11].

- Reduction of forecast error of medium to large scale wind farms [12].

- Diminishing the sharp variations in wind farm output [13]. 
- Peak shaving to differ reinforcements [14].

- Improving the power quality for sensitive loads in microgrids [15].

- Reducing energy losses in a system with high penetration of DG [16].

Many of the studies carried out to investigate these applications (particularly those related to DG) have looked at the control mechanism of energy storage by setting predefined cycles of charging and discharging, assuming perfect response against the constraint being managed (i.e., no uncertainties). However, the actual formulation/implementation of the realtime controller requires considering the variable power output behavior of renewable DG plants.

In this work, a hybrid controller of an energy storage system and a wind farm is proposed in order to actively manage the congestion (thermal constraint) of a corridor. The proposed control mechanism is novel in the way it handles the uncertainties (i.e., errors) resulting from the changing states of generation and demand. This requires adding more intelligence to the controller to cope with sudden gusts or periods of low power output, thus avoiding wrong decisions and harvesting more wind energy instead of being curtailed.

The performance of the proposed hybrid controller will be assessed on an hourly basis using a radial feeder and real-life historic wind and demand hourly data for a year. The controller is modeled and coded in the Open Source Distribution System Simulator (OpenDSS) developed by EPRI [17], and interfaced with VBA programming language.

\section{PROBLEM Formulation}

\section{A. Objective of the Hybrid Controller}

Fig. 1 shows a rural feeder with a wind farm connected to the remote end. During maximum demand $(5 \mathrm{MW})$, it is possible for the wind farm to produce its rated output (10MW) without overloading the overhead line (max 6MVA). However, in a scenario with minimum load, say $(1 \mathrm{MW})$, and maximum generation, thermal limits of the line would be exceeded by (3MW or $50 \%$ ). The only way this particularly wind farm could connect would be either by a non-firm generation arrangement or by actively controlling its output (i.e., curtailing it) according to the power flows through the line.

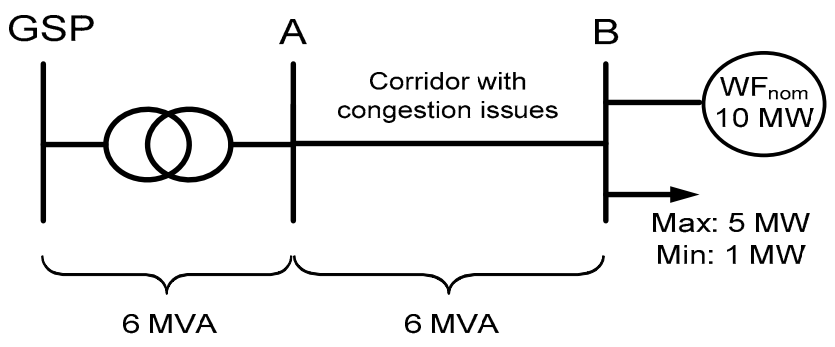

Fig. 1 Example of a rural feeder with a wind farm.

Assuming the active management of the wind farm, if a storage facility is also installed at the same location then it would be possible to control them both in a way that the thermal constraint of the line is catered for and the curtailment is minimized.

Consequently, the objective of the proposed hybrid controller is two-fold: to maintain the power flow through a given monitored corridor/line below its thermal limit, and to maximize the capacity factor of the renewable DG plant by preventing curtailment as much as possible.

This is done by firstly using the energy storage to deal with problems of overloading. If the storage system reaches its maximum energy or power capacity, and it is not enough to alleviate the congestion issue, then the controller resorts to apply curtailment to the wind farm. Given the variability of wind, the controller design should also take into account not to completely fill the storage capacity in order to create a 'reserve' for critical cases.

\section{B. Monitored Corridor or Line}

The variability of the power flow through the monitored corridor imposes a significant challenge on the controller given that a decision made for the current state (e.g., current 15-min period or hour) might not necessarily be suitable for the next one (wind power output, particularly, could change significantly). For instance, if a discharge action is initiated and a sudden gust occurs, this may lead to an overload.

In order to avoid undesirable scenarios, certain thresholds should be defined to prevent the unnecessary operation of the storage system. To achieve this, historical data is statistically analyzed. Time-series profiles of wind and demand are combined to produce the power flow through the monitored corridor. These values are then divided in different states which consider direction (forward/reverse) and magnitude of the power flow. Finally, the probability of the transition from one state to another can be calculated. With this statistical information, the storage system can be prevented from discharging or charging in states that are likely to be exposed to significant changes (transitions in the power flow direction/magnitude) in the next control cycle. In addition, for the current state, an average transition (in $\mathrm{kW}$ or MW) could also be computed to identify limits for the charging or discharging actions.

Mathematically, the methodology breaks the power flow profile of the corridor into $N$ forward states and $M$ reverse states by finding out the maximum $\left(P_{F \max }\right)$, the minimum $\left(P_{F m i n}\right)$ forward power flow values, and, similarly, the maximum $\left(P_{R \max }\right)$, the minimum $\left(P_{R \min }\right)$ reverse power flow values. Then, uniform distances between forward states $(\Delta F)$ and uniform distances between reverse states $(\Delta R)$ are computed as shown in (1) and (2).

$$
\begin{aligned}
\Delta F & =\frac{\left(P_{F \max }-P_{F \min }\right)}{N} \\
\Delta R & =\frac{\left(P_{R \max }-P_{R \min }\right)}{M}
\end{aligned}
$$

For instance, if the power flow is broken into a series of six states $(N=3, M=3)$, the three ranges of states for reverse power flows will be $\left[P_{R \min }, P_{R \min }+\Delta R\right], \quad\left[P_{R \min }+\right.$ $\left.\Delta R, P_{R \min }+2 \Delta R\right]$ and $\left[P_{R \min }+2 \Delta R, P_{R \max }\right]$. The three ranges of states for forward power flows will be $\left[P_{F m i n}, P_{F m i n}+\Delta F\right], \quad\left[P_{F m i n}+\Delta F, P_{F m i n}+2 \Delta F\right], \quad$ and $\left[P_{F \min }+2 \Delta F, P_{F \max }\right]$.

After that, the probability of a direction transition (change in the direction of the power flow), $B(i, j)$, and the magnitude of the transition, $P_{a v}(i, j)$, from the current state $i$ to the next 
state $j$ (e.g., next hour), are computed and repeated for all the possible combinations of transitions between all the defined ranges of states. For example, if from the historical data there are found 30 transitions of $1 \mathrm{MW}$ and 70 transitions of $2 \mathrm{MW}$ from state "a" to state "b", then the expected magnitude of the transition $P_{a v}(a, b)$ will be $0.3 \times 1+0.7 \times 2=1.7 \mathrm{MW}$. In addition, if from the same data it is found that the probability of transitioning from a load-led power flow to a reverse one (due to excess in local generation) is 0.4 , then $B(a, b)=0.4$.

Finally, the most likely variation in the power flow magnitude that the corridor will be exposed to in the next state, $T(i)$, is calculated as shown in (3). This will be used to prevent undesired storage actions.

$$
T(i)=\sum_{j=1}^{N+M} P_{a v}(i, j) * B(i, j)
$$

For instance, $T(4)=-7 \mathrm{MW}$, means that it is very likely that power flow through the corridor in state 4 will change from its current value to $7 \mathrm{MW}$ less in the next state. Accordingly, the controller will block storage discharge operation since it is more probable that discharging power at this state will lead to increased congestion problems in the next control cycle.

\section{Energy Storage System Modeling}

The storage system is basically modeled as a generator that can be dispatched to produce power (discharge) or a load which consumes power (charge) within its power rating $\left(P_{\text {rated }}\right)$ and its energy storage capacity $\left(E_{\text {rated }}\right)$. In addition, the rate of charge $\left(R_{C}\right)$, and the rate of discharge $\left(R_{D}\right)$ are calculated by relating the required charge/discharge power to the power rating of the storage - these values should not exceed $100 \%$. Moreover, the model takes into account energy losses inside the storage by allowing separate specification of charging efficiency $\left(\eta_{C}\right)$, and discharge efficiency $\left(\eta_{D}\right)$, both parameters ultimately affecting the stored energy $\left(E_{\text {stored }}\right)$ and the power output $\left(P_{O}\right)$ of the storage facility as shown in (4), (5), and (6).

$$
\begin{gathered}
E_{\text {stored }}^{\text {new }}=E_{\text {stored }}^{\text {old }}+R_{C} * P_{\text {rated }} * \eta_{C} \\
E_{\text {stored }}^{\text {new }}=E_{\text {stored }}^{\text {old }}-R_{D} * P_{\text {rated }} * \eta_{D} \\
P_{O}=R_{D} * P_{\text {rated }} * \eta_{D}
\end{gathered}
$$

Here, the corresponding storage capacity in the proposed model is classified in the following thresholds or regions, as shown in Fig. 2:

- Maximum Stored Energy $\left(E_{\max }\right)$ : maximum energy that can be stored considering that a storage reserve (upper reserve) will always be kept.

- Upper Reserve Energy $\left(E_{\text {res }}\right)$ : reserve energy to cope with sharp increases in wind generation that might congest the corridor, i.e., $E_{\text {res }}+E_{\max }$ represents the total nominal capacity of the storage system.

- Minimum Stored Energy $\left(E_{\text {min }}\right)$ : minimum energy that should be maintained at all times (not to be utilized during any discharge operation) to preserve the life span of the storage facility.

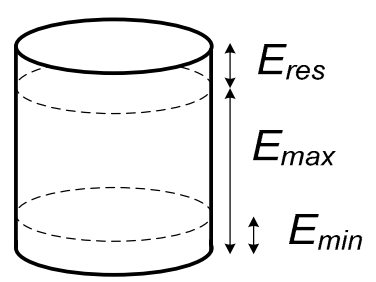

Fig. 2 Storage levels.

\section{Hybrid Controller Mechanism}

Based on the power flow through the monitored corridor, the controller will decide the corresponding action to be taken by either the storage facility or the wind farm in the next duty cycle (e.g., minute, hour, etc.) in order to reduce the impact of reverse power flows produced by the wind farm. The following two scenarios are considered:

1) Power Flow within the Thermal Capacity

During load-led power flows the storage will change its state into discharging mode in a way that the rate of discharge, $R_{D}$, is such that $E_{\text {stored }}>E_{\text {min }}$ in order to preserve the life span of the storage system.

During reverse power flows (that do not exceed the thermal capacity) the storage system will charge such that the corresponding rate, $R_{C}$, is bounded by an inequality that guarantees that $E_{\text {stored }}$ will be below $E_{\text {max }}$, as shown in (7).

$$
R_{C} \leq \frac{E_{\text {max }}-E_{\text {stored }}}{P_{\text {rated }}}
$$

In addition, charging and discharging percentages are computed in a way to handle the transitions that may affect the the current power flow through the monitored corridor, $S_{\text {corr }}$, in the next control cycle as shown in (8) and (9), and as presented in section II-B.

$$
\begin{aligned}
& R_{D}=\frac{\left|S_{\text {corr }}\right|-|T(i)|}{P_{\text {rated }}} \\
& R_{c}=\frac{\left|S_{\text {corr }}\right|-|T(i)|}{P_{\text {rated }}}
\end{aligned}
$$

In some instances, after a charging cycle is applied due to congestion, the storage system may become full, i.e., $E_{\text {stored }}$ exceeds the pre-defined $E_{\max }$. This means that the storage will no longer be capable to alleviate the congestion issue on its own. The wind farm would need to be curtailed if the congestion problem persists. To minimize this situation, discharge is allowed during reverse power flows to free up storage capacity so it can be used later. However, for this, the probabilities of the transitions to the next state have also to be taken into account.

\section{2) Power Flow Leading to Congestion}

The control strategy for DG and energy storage adopted in this scenario is illustrated in Fig. 3 and it is detailed as follows. 


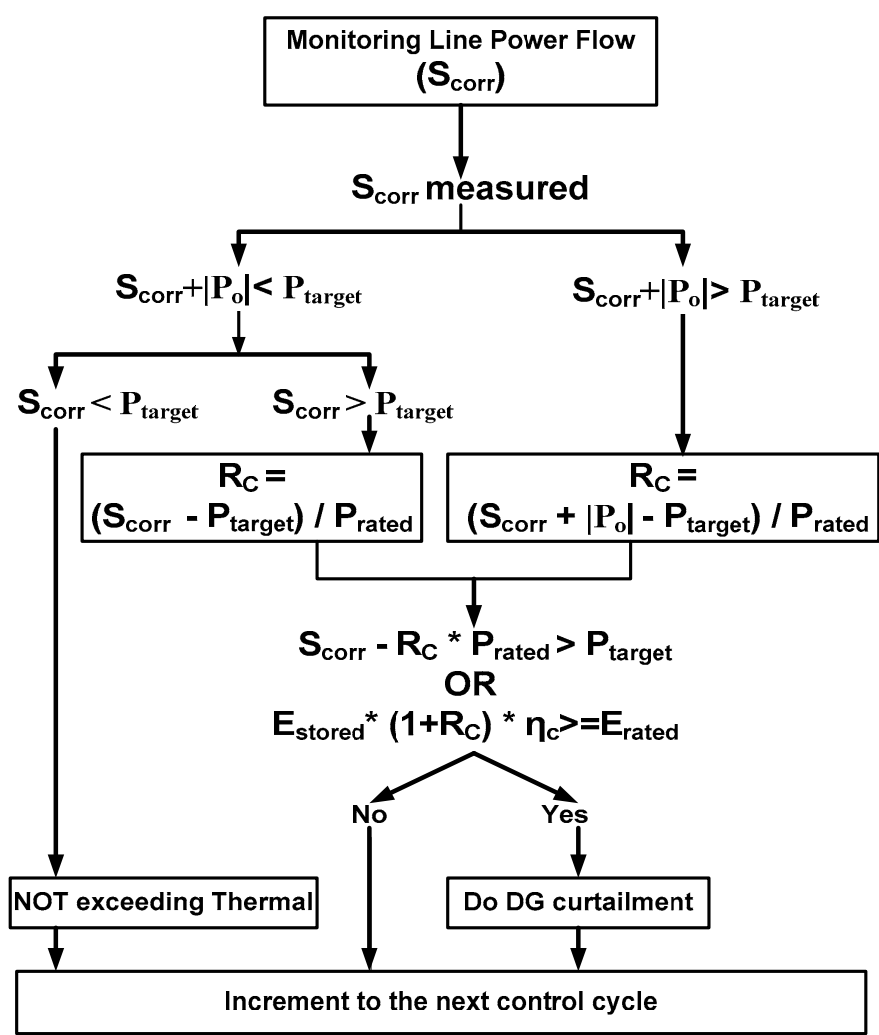

Fig. 3 Flow chart of Hybrid controller strategy when power flow exceeding the thermal constraint in the corridor.

First, a simple technique is deployed, where the control scheme will make the storage system charge, with a rate as shown in (10), when the power flow through the monitored corridor exceeds a target $\left(P_{\text {target }}\right)$ equal to $90 \%$ of its nominal capacity.

$$
R_{C}=\frac{S_{\text {corr }}-P_{\text {target }}}{P_{\text {rated }}}
$$

However, this simple technique is not enough to cope with congestion for a number of consecutive hours. For instance, assuming the example from Fig. 1, if the power flows through the corridor in three consecutive hours are $6.1 \mathrm{MW}, 6 \mathrm{MW}$, $6.5 \mathrm{MW}$, then the thermal capacity is constantly exceeded. According to the simple technique, the controller in the first hour will detect that the power flow is higher than the threshold of $90 \%$ (i.e., $P_{\text {target }}=5.4 \mathrm{MW}$ ), so it will make the storage system (say $P_{\text {rated }}=1 \mathrm{MW}$ ) charge with $R_{C}=70 \%$. This charging power would be applied in the subsequent hour causing the power in the corridor to be 5.3MW (6MW$0.7 \mathrm{MW}$ ) which is below than the target. For the third hour, the controller will request the storage to stop charging and return back to the idling state. Nonetheless, during the third hour the power flow exceeds again the target but this is not necessarily 'seen' by the controller.

In order to tackle these and similar issues, the proposed hybrid controller estimates in each control cycle the power that, without storage, would flow through the corridor, and then makes a 'more informed' decision based on this value. For instance, in the previous example for consecutive congestion, during the second hour the controller calculates the power flow without storage (i.e., $5.3+0.7=6 \mathrm{MW}$ ). Given that this value is above the target (i.e., congestion is still happening), it will make the storage to charge in the third hour with $R_{C}=60 \%$, causing the power flow to reduce to $5.9 \mathrm{MW}$ in the third hour (which is below the nominal capacity).

In addition, the proposed controller considers that the power output of the wind farm has to be curtailed $10 \%$ (i.e., power output set point reduced by 0.10p.u. based on its nominal capacity) when the storage system reaches its maximum energy or power capacity. The wind farm's power output $\left(P_{G}\right)$ is calculated using (11), where $S_{G}$ is its nominal capacity in MW, $\omega_{m}$ is the wind power availability in p.u. (at that hour), and $\tau$ is the power output set point (which varies according to curtailments actions). If curtailment is required, $\tau$ will be decreased by 0.1 p.u. When congestion is not a problem, the power flow through the corridor is below $30 \%$ of its capacity, $\tau$ will be increased by 0.1 p.u. until the wind farm goes back to normal operation.

$$
\begin{aligned}
P_{G}= & S_{G} * \omega_{m} * \tau \\
& \text { III. CASE STUDY }
\end{aligned}
$$

In order to demonstrate the effectiveness of the proposed hybrid controller for congestion management, three cases will be contrasted: no control (i.e., no storage and no curtailment), active management of the wind farm (i.e., curtailment is applied), and the hybrid controller. The simulations are carried out over a year with hourly data.

\section{A. Radial Distribution Feeder}

Fig. 4 shows a radial distribution feeder with a total length of $5 \mathrm{~km}$ and it is supplied by two identical 5 -MVA $33 / 11-\mathrm{kV}$ transformers. The loads (peak values shown in Fig. 4) have a power factor of 0.95 inductive. A wind farm of $10 \mathrm{MW}$ is connected to the remote end. Adopted demand and wind profiles correspond to data from central Scotland in 2003 [18]. The total energy that could be produced by the wind farm, without curtailment, is $36.23 \mathrm{GWh} /$ year. This results in a very healthy capacity factor of $41.4 \%$.

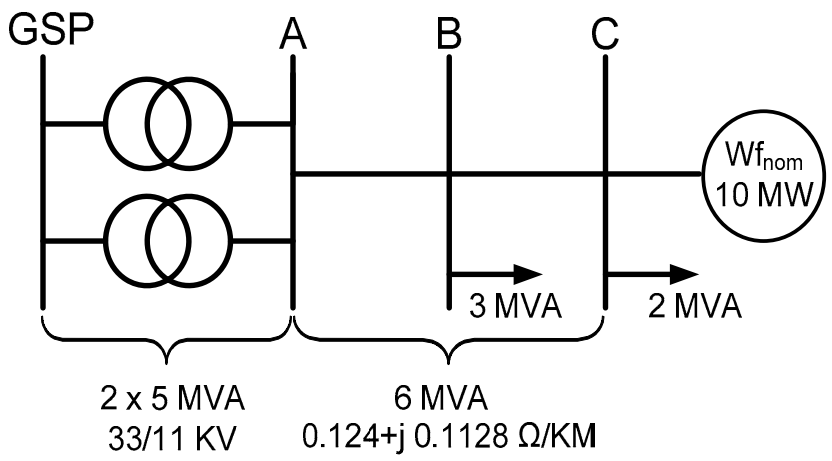

Fig. 4 Simple rural feeder with a wind farm - Case Study.

In a Business as Usual (BAU) scenario, where no active network management is deployed, the maximum reverse power flow in line section A-B is 7.8 MVA and, as expected, would exceed the thermal limit of the line (in this case by $30 \%$ ). In addition, the line would suffer from congestion (i.e., overloading) for 1319 hours during the year. 


\section{Accepted Paper}
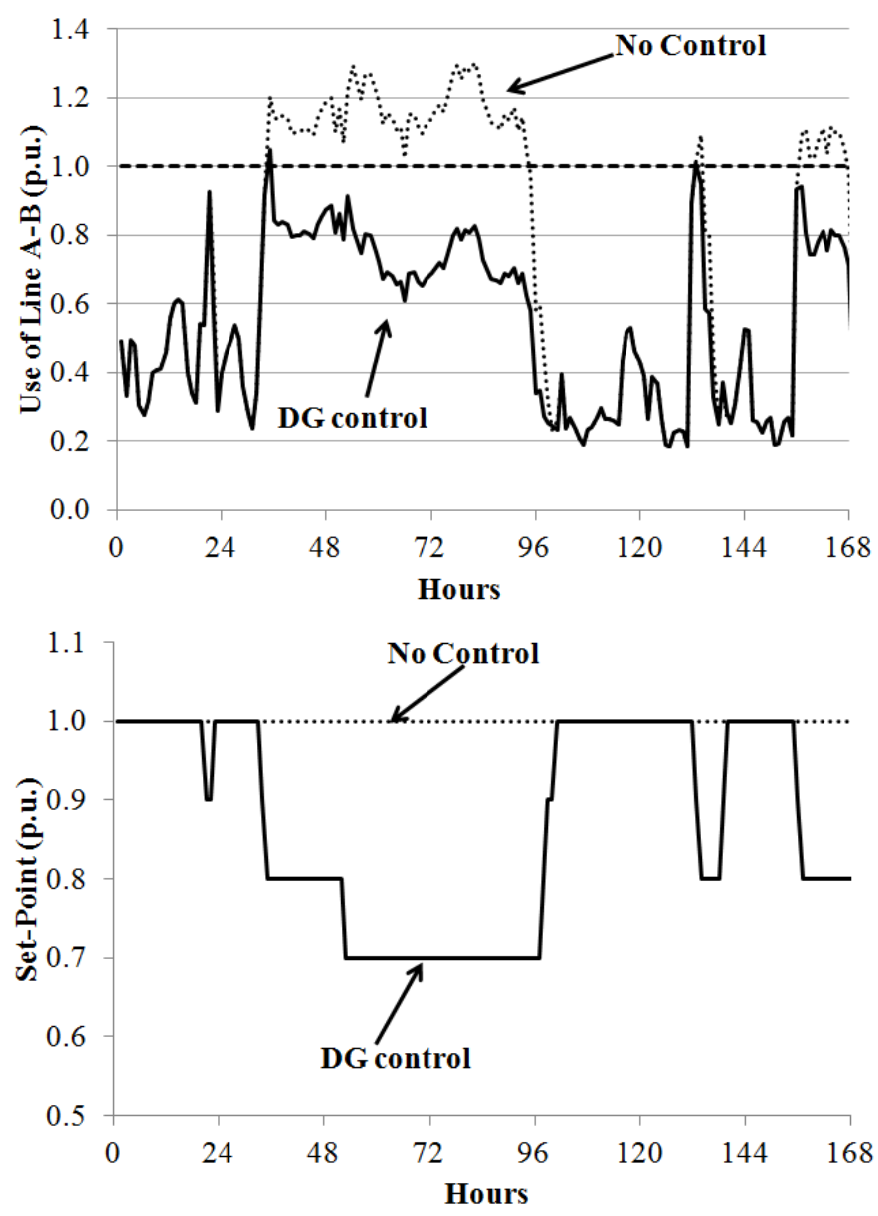

-DG Control $\cdots$ BAU (No Control)

Fig. 5 (Top) Capacity usage of line A-B (p.u.). (Bottom) Wind farm's power set-point (p.u.) with and without active management of wind farm for the $3^{\text {rd }}$ week in June 2003.

\section{B. Incorporating Active Management to the wind farm}

Fig. 5 (top) shows the power flow profile in line section A$\mathrm{B}$ with and without active management of the wind farm (i.e., only curtailment is applied, no storage). It can be noticed that under BAU scenario (i.e., no control) the loading of line A-B exceeds the thermal constraints for significant consecutive hours. With ANM scenario, when the power flow at each hour exceeds a loading of $90 \%$, the scheme will be activated and the set point of the wind farm will be reduced by 0.1 p.u.

The energy produced for a year by the wind farm using this scheme is $32.26 \mathrm{GWh}$, resulting in a capacity factor of $36.8 \%$ or $4.3 \mathrm{GWh}$ curtailed. The number of hours exceeding the thermal limit of the line decreases significantly, down to 73 .

\section{Incorporating Storage-Hybrid Controller}

A storage facility is now considered at the same location of the wind farm in Fig. 4. The proposed hybrid controller is applied to manage the congestion of line section A-B. First, the method used to extract useful probabilities from the historical power flow profile of the monitored corridor (deduced from historical load and generation profiles) is detailed. Then, the impacts of storage parameters on the capacity factor of the wind farm are discussed.

The procedures presented in section II-B are used for line A-B. From the historic power flow profile data of the corridor,
TABLE I

TRANSITION PROBABILITY MATRIX

\begin{tabular}{c|c|c|c|c|c|c}
\hline $\begin{array}{c}\text { Next State } \\
\text { Current State }\end{array}$ & 1 & 2 & 3 & 4 & 5 & 6 \\
\hline 1 & $83 \%$ & $15 \%$ & $2 \%$ & 0 & 0 & 0 \\
\hline 2 & $19 \%$ & $54 \%$ & $24 \%$ & $2 \%$ & 0 & 0 \\
\hline 3 & $2 \%$ & $19 \%$ & $52 \%$ & $22 \%$ & $5 \%$ & 0 \\
\hline 4 & 0 & $2 \%$ & $24 \%$ & $50 \%$ & $23 \%$ & $1 \%$ \\
\hline 5 & 0 & 0 & $3 \%$ & $14 \%$ & $74 \%$ & $8 \%$ \\
\hline 6 & $1 \%$ & 0 & 0 & $1 \%$ & $21 \%$ & $77 \%$ \\
\hline
\end{tabular}

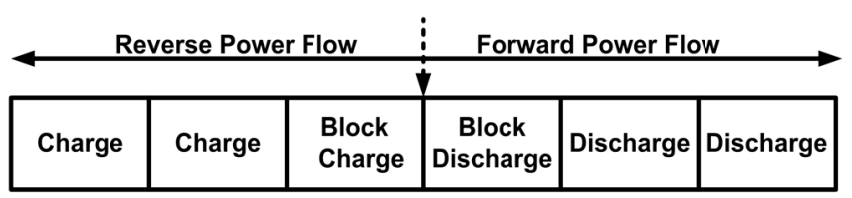

Fig. 6 Blocking regions for charging and discharging the energy storage.

during reverse power flows, $P_{R \max }$ and $P_{R \min }$ were 7.5 and $0 \mathrm{MW}$, respectively. For the load-led power flows, $P_{F \max }$ and $P_{\text {Fmin }}$ were 4.8 and $0 \mathrm{MW}$, respectively. Then, by applying (1) and (2), this profile is broken into six states. To illustrate the process, three states for reverse power flow with ranges $[0,2.5],[2.5,5]$, and $[5,7.5] \mathrm{MW}$ indexed by "3", "2", and " 1 ", respectively, are used. Three other states for load-led power flows with ranges [0,1.6], [1.6,3.2], and [3.2.4.8] MW, indexed by "4", "5", and "6", respectively, are also used.

The transition probability matrix is built by finding all the possible combinations of transitions between all the states as depicted in Table I. It can be noticed from the analysis that it is more likely for a sudden change in the direction of the power flow to occur if the current power flow lies within states 3 and 4 .

Finally, the blocking regions for charging or discharging actions are identified as shown in Fig. 6.

\section{Impact of Energy Storage Parameters on the Wind Farm's Capacity Factor}

In this section, the upper reserve of energy storage $\left(E_{\text {res }}\right)$ and the storage size $\left(P_{\text {rated }}, E_{\text {rated }}\right)$ parameters are examined in relation to their impact on the wind farm's final capacity factor. This is accomplished by comparing the difference of curtailed energy between active management of the wind farm with and without storage, varying one of the parameters of the storage system.

1) Upper Reserve $\left(E_{\text {res }}\right)$

Fig. 7 (top) shows a snapshot for demonstrating the timeseries operation of the hybrid controller when allocating upper reserve. A storage system of $1000 \mathrm{~kW}, 3000 \mathrm{kWh}$ with upper reserve of $1500 \mathrm{kWh}$ (i.e., $50 \%$ of the rated capacity) is used. When the controller measures a power flow through the corridor higher than $90 \%$, it will make the storage to charge using (10), so as to bring the power flow below the target. Consequently, the wind farm is able to operate with nominal settings.

Unless the upper reserve is defined, the storage system will be allowed to reach its rated energy capacity before it could be 

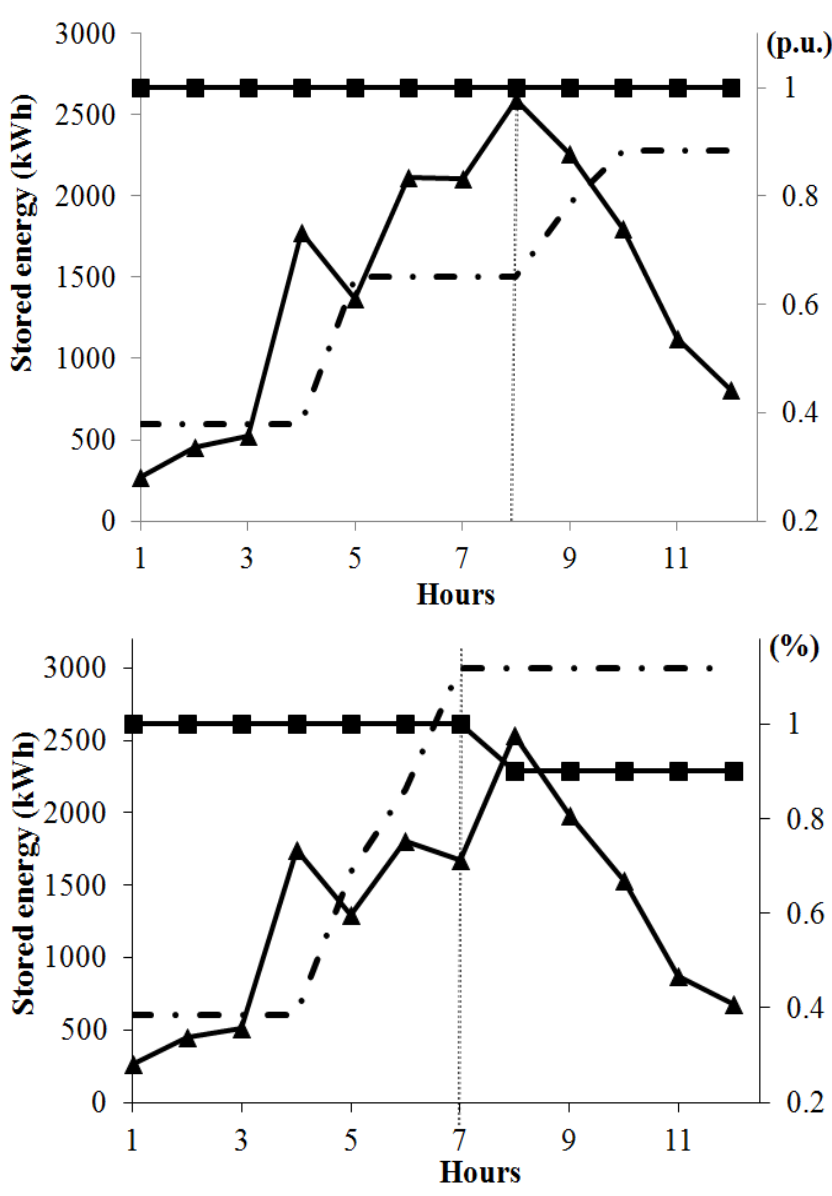

- Stored energy $(\mathrm{kWh})$-Use of Line A-B (\%) - - Set-Point \%

Fig. 7 Use of line A-B p.u. (right), set-point (p.u.) (right) and stored energy (left) for the operation of the hybrid controller. Using upper reserve of $50 \%$ (top) and without upper reserve (bottom). Storage system of $1000 \mathrm{~kW}$, $3000 \mathrm{kWh}$ for a block of six hours.

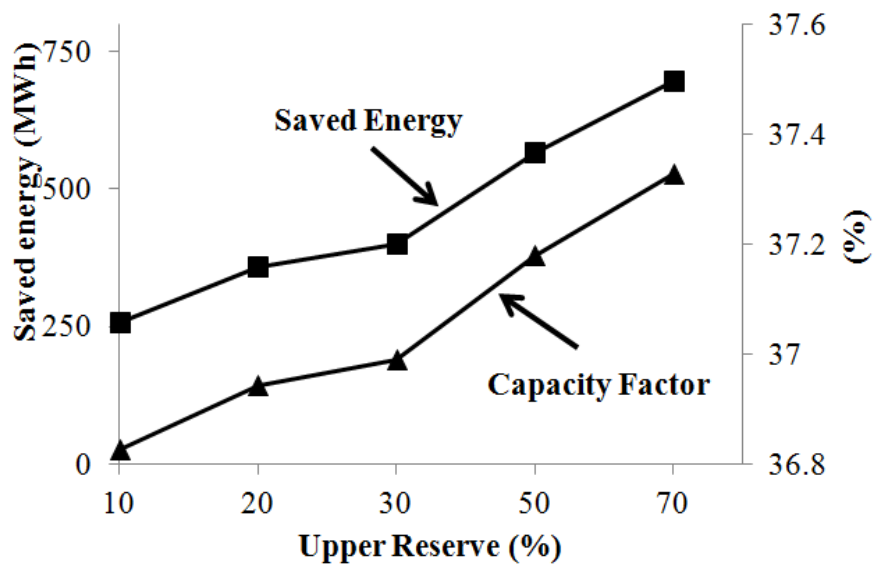

Fig. 8. Saved energy in MWh (right) and capacity factor percentage (left) for one year by applying $(1000 \mathrm{~kW}, 3000 \mathrm{kWh})$ energy storage with different upper reserve percentages.

used to solve a congestion issue. Consequently, if there is no upper reserve (Fig. 7, bottom), the controller will curtail the wind farm's power output to cope with the congestion.

Fig. 8 shows the amount of 'saved energy' (i.e., not curtailed) versus different upper reserve energy percentage for

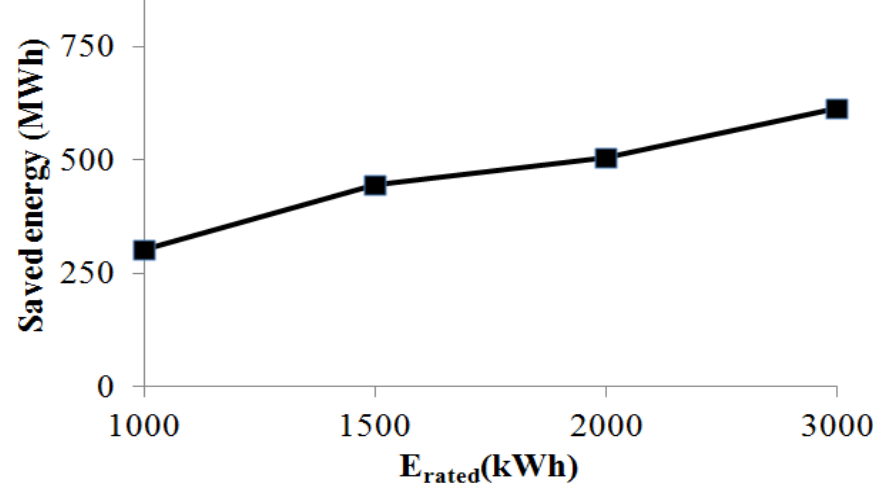

Fig. 9 Saved energy for one year versus different storage energy capacity and with power rating of $(500 \mathrm{~kW})$.

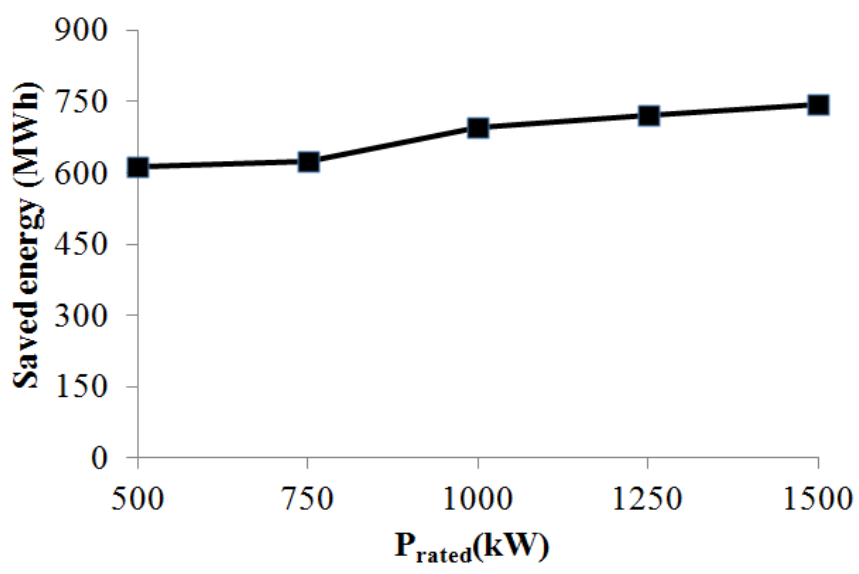

Fig. 10 Saved energy for one year versus different storage power capacity and with energy capacity of (3000kWh).

$(1000 \mathrm{~kW}, 3000 \mathrm{kWh})$ storage. This figure shows that the saved energy will be increased by rising the upper reserve percentage. For instance, the saved energy with deploying upper reserve of $70 \%(2100 \mathrm{kWh})$ will save energy three times that with upper reserve of $10 \%(300 \mathrm{kWh})$.

2) Energy Storage Size $\left(P_{\text {rated }}, E_{\text {rated }}\right)$

Fig. 9 shows the saved energy versus different storage energy capacities $\left(E_{\text {rated }}\right)$ and with a power rating of $500 \mathrm{~kW}$. This figure indicates that the saved energy increases with the growth in the energy capacity of the storage. This is because the storage system will be capable to accept more energy without the necessity of curtailing the wind farm should congestion occurs.

Fig. 10 shows the saved energy versus different storage power capacities $\left(P_{\text {rated }}\right)$ and with energy capacity of $3000 \mathrm{kWh}$. This figure illustrates that there is a maximum cap for the saved energy that can be achieved for storage with specific energy capacity. According to the studied cases, the maximum saved energy is achieved when the power capacity is $1000 \mathrm{~kW}$, and the saved energy will not improve despite the increase in the power capacity.

\section{E. Hybrid Controller Scheme}

The power flow profile in line section A-B with active management of the wind farm using hybrid controller approach method is shown in Fig. 11 (considering the same week as in Fig. 5). It can be noticed that the performance of the hybrid controller in terms of the loading of line A-B is 


\section{Accepted Paper}

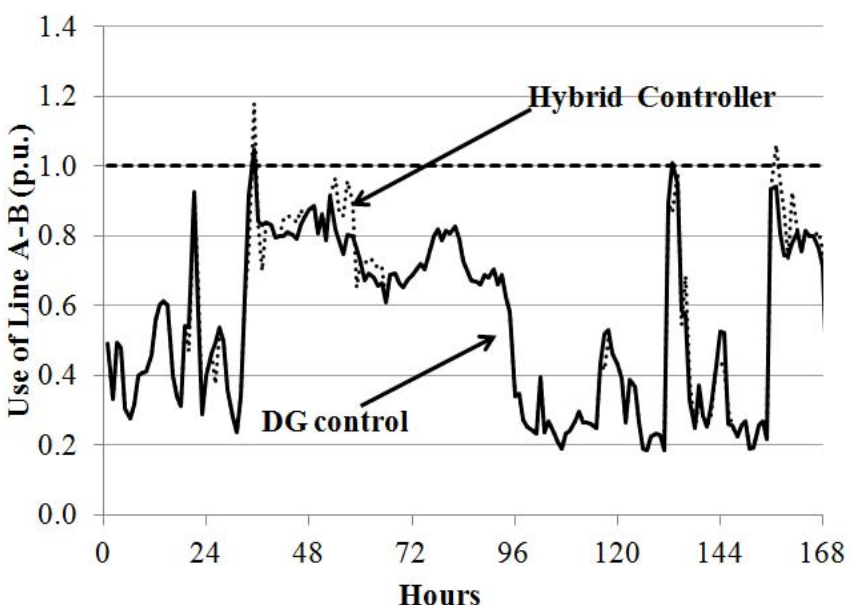

Fig. 11 Capacity usage of line A-B (p.u.) with DG active management and hybrid controller scheme for $(1000 \mathrm{~kW}, 3000 \mathrm{kWh})$ storage with upper reserve of $50 \%$ for the $3^{\text {rd }}$ week in June 2003 .

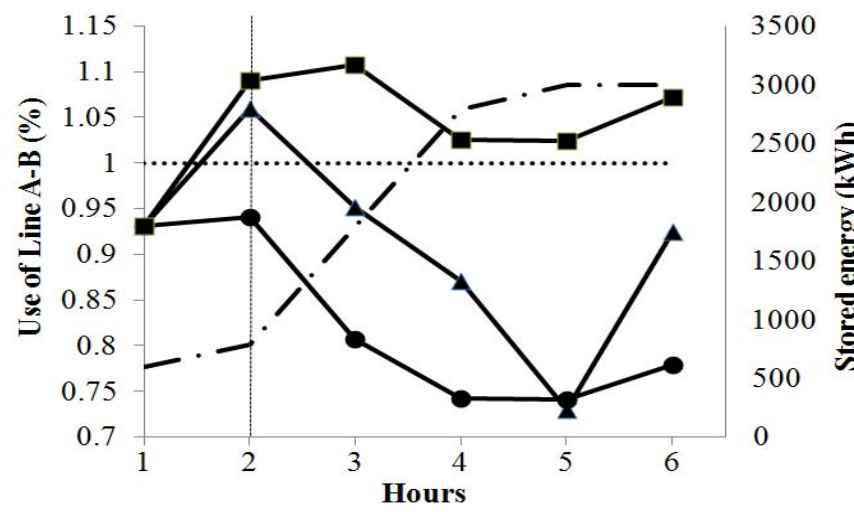

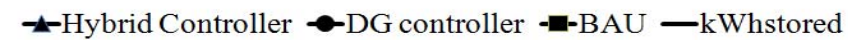

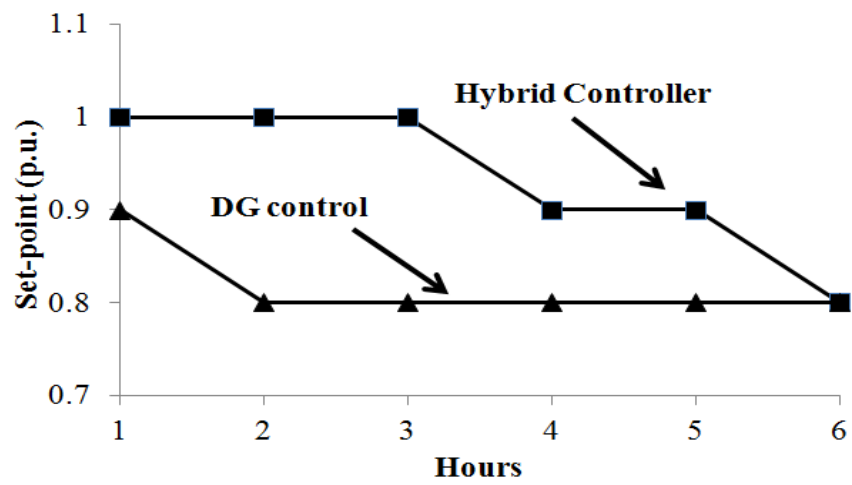

Fig. 12 (Top- left axis) Use of line A-B (p.u.), (top-right axis) stored energy and (bottom) set-point (p.u.) using BAU, DG active management and hybrid controller scheme for $(1000 \mathrm{~kW}, 3000 \mathrm{kWh})$ storage with upper reserve of $50 \%$ for a block of six hours.

very similar to that using the DG controller. However, the main difference is that it increases the usage of the line as a consequence of a more intelligent harvesting. For this particular week and case, the average usage of the line A-B went from $54.9 \%$ to $55.5 \%$. For the whole year (same case), this figure went from $53.4 \%$ to $53.8 \%$. In terms of the wind farm's capacity factor, it went from $36.5 \%$ to $37.2 \%$. While changes in the upper reserve can lead to better results (Fig. 8), these modest improvements demonstrate the proposed algorithm works. Further refinements should include intelligent response to high frequency variations in the wind profile.

Fig. 12 shows a snapshot for demonstrating the capability of hybrid controller to operate the wind farm without violating the thermal constraints. It also indicates that the scheme allows increasing the wind farm's capacity factor compared with only-curtailment approach.

In Fig. 12 (top), the usage percentage of line A-B is below the thermal limit when the hybrid controller is adopted. In the second hour, the hybrid controller detects congestion in the corridor (power flow above the target of 90\%), so to counteract this, the storage starts charging in the successive hours until it reaches its energy capacity $(3000 \mathrm{kWh})$. Then, curtailment will be triggered as the last resort (the wind farm's power output set point is decreased by 0.1 p.u.). On the other hand, with the deployment of the controller without storage, the Fig. 12 shows that curtailment will be used in each hour the power flow exceeds the target.

\section{CONCLUSIONS}

This paper presents a (pseudo) real-time hybrid controller of wind power and energy storage to actively manage congestion. The proposed mechanism is implemented to mitigate thermal overloads in a monitored corridor by firstly using the energy storage system to deal with it, resorting afterwards to the use of curtailment. Results confirm that the proposed scheme is capable of actively managing congestion, whilst maximizing the harvesting of low-carbon electricity.

The proposed control mechanism provides a solution that could be used by DNOs and DG developers to connect greater volumes of renewable generation capacity without significantly compromising capacity factors, and without the need of expensive network reinforcement.

In this work, the control used a fixed window with 8760 points (hours) from the historical power flow data to assist the operation of the hybrid controller. For its actual implementation, this historical window should be updated dynamically to cater for probable changes in the demand and the wind profile due to seasonal variations and network changes. Future work will cover the impact of the window structure (fixed versus adaptive) and its size on the performance of the controller.

This work will also be extended to assess the economics behind the proposed hybrid approach taking into account that the future regulatory framework in the UK (RIIO, Revenue = Incentive + Innovation + Output) will explicitly incentivize innovation from DNOs in order to meet the country's target in terms of renewables and $\mathrm{CO}_{2}$ emissions.

Finally, future work will also look at centralized approaches to control multiple DG-storage schemes.

\section{REFERENCES}

[1] R. C. Dugan, "Challenges in considering distributed generation in the analysis and design of distribution systems," in Proc. IEEE Power Energy Soc. Gen. Meet., Pittsburgh, PA, Jul. 2008, pp. 1-6.

[2] R. A. Walling, R. Saint, R. C. Dugan, J. Burke, and L. A. Kojovic, "Summary of distributed resources impact on power delivery systems," IEEE Trans. Power Del., vol. 23, no. 3, pp. 1636-1644, Jul. 2008.

[3] L. F. Ochoa, A. Padilha-Feltrin, and G. P. Harrison, "Evaluating distributed time-varying generation through a multiobjective index," IEEE Trans. Power Del., vol. 23, no. 2, pp. 1132-1138, Apr. 2008 


\section{Accepted Paper}

[4] L.M. Cipcigan,P.C. Taylor,P. Trichakis, "The impact of small scale Wind Generators on LV Distribution System Voltage," in Proc. of Clean Electrical Power,Conference, 2007, pp.1-7.

[5] E.On Central Networks. (2011, April). Registered Power Zone. [Online]. Available:http://www.eonuk.com/distribution/registeredpowerzone.aspx

[6] P.J.Hall and E.J.Bain, "Energy-storage technologies and electricity generation," Energy Policy, vol. 36, pp. 4352-4355, 2008.

[7] J.Baker,"New technology and possible advances in energy storage," Energy Policy, vol. 36, pp. 4368-4373, 2008.

[8] G.Coppez, S. Chowdhury and S.P. Chowdhury, "Impacts of energy storage in distributed power generation: a review," in Proceedings of 2010 International Conference on Power System Technology, 2010, pp. $1-7$.

[9] P. Poonpun and W. T. Jewell, "Analysis of the Cost per Kilowatt Hour to Store Electricity," IEEE Transactions on Energy Conversion, vol. 23, no. 2, pp. 529-534, April 2008.

[10] K.C. Divya and J. Østergaard, "Battery energy storage technology for power systems-an overview "Electric Power Systems Research, vol. 79, pp. 511-520, April 2009.

[11] N.S. Wade, P.C. Taylor, P.D. Lang, and P.R Jones," Evaluating the benefits of an electrical energy storage system in a future smart grid," Energy policy, vol. 38, pp. 7180-7188, 2010.

[12] T.K.A. Brekken, A. Yokochi, A. von Jouanne, A. Yen, and H.M. Hapke," Optimal energy storage sizing and control for wind power applications," IEEE Transactions on Sustainable Energy, vol. 2, no. 1, pp. 69-77 December 2010

[13] M. Khalid, and A.V. Savkin, "Optimization and control of a distributed Battery Energy Storage System for wind power smoothing," in Proceedings 2011 19th Mediterranean Conference on Control and Automation, 2011, pp. 39-43.

[14] K.-L. Wu, C.C. Aggarwal, and P.S. Yu, "Sizing and optimal operation of battery energy storage system for peak shaving application," in Proceedings of 2007 IEEE Lausanne Powertech, 2007, pp. 621-625.

[15] R. Zamora and A. K. Srivastava,"Controls for microgrids with storage: review, challenges, and research needs," Renewable and sustainable energy, vol. 14, pp. 2009-2018, 2010.
[16] C. Abbey and G. Joos, "Coordination of Distributed Storage with Wind Energy in a Rural Distribution System," in Proceedings of 42nd Industry Applications Conference, 2007, pp. 1087-1092.

[17] OpenDSS Download. [Online]. Available: http://sourceforge.net/projects/electricdss.

[18] T. Boehme, J. Taylor, A. R. Wallace, and J. W. Bialek, "Matching renewable electricity generation with demand," Scottish Executive, Edinburgh, Feb. 2006.

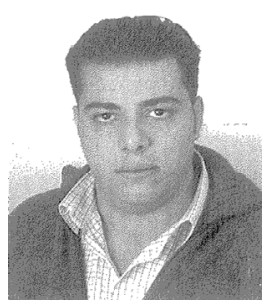

Sahban W. Alnaser (S'11) received the B.Sc. and M.Sc. degrees in Electrical Engineering from the University of Jordan, Amman, Jordan, in 2005 and 2008, respectively. He is currently pursuing the Ph.D. degree at The University of Manchester, Manchester, U.K. From 2005 to 2011 he was with the Electricity Distribution Company (EDCO) in Jordan as head of power system studies and planning section. His research interests include integration of distributed energy resources, active network management and distribution network analysis.

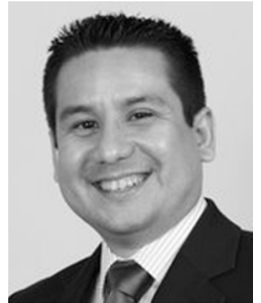

Luis F. Ochoa (S'01-M'07) is a Lecturer in Smart Distribution Networks at The University of Manchester, UK. He received the B.Eng. degree from UNI, Lima, Peru, in 2000 and the M.Sc. and Ph.D. degrees from UNESP, Ilha Solteira, Brazil, in 2003 and 2006, respectively. From 2007 to 2010, he was a Research Fellow at the University of Edinburgh, U.K.

His current research interests include network integration of distributed energy resources and distribution system analysis. 